\title{
Demographic Factors as Correlates of Health - Seeking Behaviour of the People of Oyo State, Nigeria
}

\author{
Shehu Raheem Adaramaja \\ Department of Health Promotion and Environmental Health Education, \\ Faculty of Education, \\ University of Ilorin, Ilorin, Nigeria \\ drraheemshehu@yahoo.co.uk. \\ and \\ Ogunsola Mufutau Tijani \\ Department of Physical and Health Education, \\ Emmanuel Alayande College of Education, Erelu, Oyo, Oyo State. \\ ogunsolammt2006@gmail.com \\ DOI: http://dx.doi.org/10.4314/gjds.v11i2.7
}

\begin{abstract}
This study was designed to investigate whether demographic factors could be taken as correlates of health-seeking behaviour of the people of Oyo State, Nigeria. Descriptive research design of survey type was adopted for this study. Sample size of one thousand, one hundred and fifty-two respondents were used. Demographic variables used were gender, marital status and religious affiliations.A researchers' designed questionnaire was used for data collection. The instrument used was validated by the experts in the area of health education. The reliability coefficient of o.68r was obtained through split-half method using Spearman-Brown Rank Order Correlation Coefficient.The data collected were analysed using frequency counts and percentage for demographic information while inferential statistics of Pearson Product Moment Correlation and Multiple Regression Analysis were adopted to test the four null hypotheses postulated for the study at 0.05 alpha level of significance. The result revealed that gender makes no difference because every individual needs to strive for a healthy life. In addition,marital status and religious affiliations were found to have influence in determining different ways by which individual access health behaviour or lifestyle like alcohol consumption, smoking, sexual behaviour and drug habit.
\end{abstract}


The study concludes that demographic factors like marital status and religious affiliations are correlates to health seeking behaviour among the people of Oyo State, Nigeria. Gender of the respondents makes no significant difference in relation to the health-seeking behaviour of the respondents. Recommendations made include that equal opportunity should be given to male and female on any health issue no matter the condition because every individual aspires to live a healthy life among other recommendations.

Keywords: Health, Behaviour, Correlates, Oyo State, Demographic Factors

\section{Introduction}

Human health is made up of nature and nurture. Nurture as the human behaviour is tailored towards improving the positive condition(s) of health imposed on individuals by nature as well as preventing the preventable health problems. The future of any nation has a direct relationship with the health of her people. The health of the people is an asset for the growth and development of the nation.

Health depends on the perception of individuals because the definition of well-being to individual is similar but different. Agbeko (2010) defined health as an optimal personal fitness for full fruitful creative living. Health is maintained and improved not only through the advancement and application of health science but also through the efforts and intelligent behavioural choices of the individual and society. Health is shaped by factors not entirely medical. Health is therefore not something that medical doctors provide for people, but rather, it is something an individual and community achieve by themselves. Agbeko (2010) claimed that people's attitudes to health often affect personal and societal concepts which are based on experiences and views on well-being.

Health-seeking behaviour is a process by which an individual acts to maintain the state of physical fitness and well-being that enables man to manage the physical,social and biological environments to his/her own satisfaction. Adeniyi and Ogunsola (2009) identified building conducive houses for living,managing wastes and pollution to improve the potentials and limitations endowed in individual by correcting the correctable limitations and preventing the health hazards that may result as evidences of environmental management by man.

Shehu (2005) described health behaviour as a pattern of choices constituting what one does and what one fails to do that affects fitness level and health status. Examples of such behaviour are physical activities,drug abuse, proper nutrition, alcoholism and indiscriminate sexual practices. He added that health - seeking behaviour are acts of making choices from the alternatives that are available and to the ease with which they are able to choose certain ones over others. The researchers observed that the effectiveness of using health behaviour for well-being depends largely on many factors among which demography plays a prominent role. Demographic factors are socio-economic 
characteristics of a population expressed statistically as age, gender, educational qualification, income level, marital status, occupation, religion, birth rate, death rate and size of the family ( Shehu, 2005). The identified demographic factors have positive and negative effects on man's state of health, but the improvement, corrections and preventive measures are acquired through man's health-seeking behaviour. The purpose of this study is to examine the degree of influence that the selected demographic factors of gender, marital status and religious affiliation have on individual's health behaviour of exercise, sanitation, medical check-ups, nutrition, sexual behaviour, drug and alcohol consumption, accident and safety. The demographic factors of gender, marital status and religious affiliation plays significant role in the the life of an indivividual( Shehu, 2005).

Gender role is perceived as masculine and feminine. Males are more physically fit than females who believe they are the weaker sex. Females are good environmentalists because they spend much time at home, regularly attend clinics owing to their reproductive health problems (Emiola, 2007). Shehu, et al. Yahaya, Onasanya, Ogunsakin and Oniyangi (2011) reported that females are known to be more physically inactive (less involved in physical activity) than males who have a high physical activity related energy expenditure. Males are also more involved in alcohol consumption than females. Marital status includes single, married, divorced, separated and widowed. Married women can only engage in exercise if the husband is interested unlike others not under the control of anybody (Shehu, 2005). Religion is conceived as a factor that influences female participation in physical activities especially among families of Northern Nigeria. Access to health care services is high due to the support gained from their husbands (Kay, 2006). The females also maintained adequate sanitation. Apart from the problems resulting from loneliness and inability to hide sickness by female widows, they also engage in alcohol consumption to forget sorrow (Abubakar, 2011). Harris and Thoresen (2005) opined that marital status determines the degree at which one maintains strong and healthy relationship in terms of positive behaviour, increased longevity, fewer depressive symptoms, better mental wellbeing and life satisfaction.

The three most recognised religions worldwide today are Islam, Christianity and Traditional religion. The nature of worship in Islam involves exercises such as bending, sitting or standing. Dancing in physical response to song or incantations is another exercise mostly noticeable in Christianity and Traditional religions. Performing ablution at the beginning of every prayer by every Muslims can be seen as an act of hygiene, though to the Islamic ablutionist, it is a significant way of cleansing both body and soul before God. The three religious groups discourage extra marital sexual behaviour. Both Traditional and Christianity religions allow alcohol consumption while Islam frowns at it. Abubakar (2011) claimed that Islamic religion viewed participation in sport as antireligious because of smart looking sports wears and mode of dressing involved in sports participation. The need to encourage behaviour modification in individuals who are at risk is of paramount importance. An attempt to make sourcing for well-being easier and convenient for the individuals has prompted the researchers to investigate the influence of demographic factors on health-seeking behaviour of the people of Oyo State,Nigeria. 


\section{Statement of the Problem}

Health behaviour refers to a combination of healthy, unhealthy, health damaging and health maintaining acts which have great effects on the state of health of individuals. Many people know that eating balanced diet, engaging in regular and moderate exercise, having regular medical check-ups and living in conducive houses are good for health, yet they refuse to observe them. Shehu (2005) observed that many people think that just having a medical check-up without any specific reason can bring to light certain health problems like high cholestrol, high blood sugar and high blood pressure that could make one feel sick overnight. Shehu et al. (2011) opined that one should have regular health and medical check-up done to promote good health. On the contrary, people engage in unproductive negative behaviours in terms of smoking, alcohol, drug abuse, poor waste management and indiscriminate sexual practices. This often leads to various degrees of infections, overweight, underweight, obesity, accident and untimely death among others. The health hazards that the mode of health behaviour imposes on people and its effects on security and economy of individuals and society are of great concern. Certain factors are believed to be influential towards these negative health behaviours. Despite series of researches conducted on health behaviours such as (Ogunsola, 2011; Adeniyi and Ogunsola Emiola 2006; Shehu 2005; Fawole et al. Egbekhare, Itiola, Odejide and Olayinka 2006) on the importance of adequate nutrition, exercise and regular medical check-ups among others, negative behaviours are still rampant. This study therefore investigated the degree of correlation existing among gender, marital status and religious affiliation on health-seeking behaviour of the people of Oyo State, Nigeria with a view to making recommendation(s) for improve health seeking behaviour.

\section{Research Questions}

The following research questions were answered:

1. Does gender of the respondents be a correlate of health seeking behaviour of the people of Oyo State, Nigeria?

2. Does marital status of the respondents be a correlate of health seeking behaviour of the people of Oyo State, Nigeria?

3. Does religious affiliation of the respondents be a correlate of health seeking behaviour of the people of Oyo State, Nigeria?

\section{Purpose of the Study}

The study investigates whether gender,marital status and religious affiliations of the respondents would be correlates of health-seeking bahaviour of the people of Oyo State, Nigeria. 


\section{Research Hypotheses}

The following research hypotheses were postulated and tested:

1. Gender of the respondents would not be a significant correlate of health seeking behaviour of the people of Oyo State, Nigeria.

2. Marital status of the respondents would not be a significant correlate of health seeking behaviour of the people of Oyo State, Nigeria.

3. Religious affiliation of the respondents would not be a significant correlate of health seeking behaviour of the people of Oyo State, Nigeria.

\section{Methodology}

Descriptive research design of survey method was adopted for this study.The design was considered to be appropriate because the reseachers were interested in investigating the influence of demographic factors on health-seeking behaviour of the respondents as well as the perceived relationship among factors selected without manipulation. People of Oyo State were the target population with a total population of 5,580,894 ( National Population Commission, 2006 ). One thousand, one hundred and fifty-two respondents randomly selected from twelve local government areas. The sample size was seen to to be adequate enough because, Fisher et al.(1998) claimed that for any population more than 10,000, the sample size should not be less than 384. Multi-stage sampling technique was used in sample selection. In the first stage, purposive sampling technique was used to select four local government areas from each of the three senetorial districts (Oyo Central; Oyo North and Oyo South). Proportional sampling technique was used to select samples from each of the local government areas used based on their respective populations. Stratified sampling was used to select respondents across different professions (257 teachers, 132 farmers, 113 drivers, 199 traders, 59 engineers, 245 office workers and 147 artisans) available in Oyo State,Nigeria. Validated researchers' designed questionnaire was used for data collection. Split-half method was used to establish the internal consistency of reliability of the research instrument. The reliability coefficient of $r=0.68$ was obtained using Spearman-Brown Rank Order Correlation. Descriptive statistics of frequency counts and percentage were used for demographic information. Inferential statistics of Pearson Product Moment Correlation was used to determine the degree of correlation that each of gender, marital status and religious affiliation had on health-seeking behaviour while multiple regression analysis was employed to quantify the amount of contributions made to the variance in health - seeking behaviour by the combined independent variables at alpha level of significance of 0.05 . 


\section{Results}

The results of the data collected and analysed are presented as follows:

Table 1: Pearson's r results on respondents gender and health-seeking behaviour

\begin{tabular}{|l|l|l|l|l|l|l|}
\hline & $\mathrm{N}$ & $\mathrm{Df}$ & $\mathrm{R}$ & $\operatorname{Sig}(2$ tailed) & Alpha Level & Decision \\
\hline $\begin{array}{l}\text { Gender and } \\
\begin{array}{l}\text { Health-Seeking } \\
\text { Behaviour }\end{array}\end{array}$ & 1152 & 1150 & 0.037 & 0.212 & 0.05 & Accepted \\
\hline
\end{tabular}

$>0.05$ Alpha level of significant

Table 1 indicates 0.037 as the calculated $r$-value with the signifcant probability value ( $\mathrm{P}$ - value) of 0.212 computed at level of significance of 0.05 . Since the calculated p-value of 0.212 is greater than 0.05 alpha level of significance, therefore, the null hypothesis was upheld. This means that gender does not determine the respondents' health-seeking behaviour because every individual needs to be healthy no matter the condition and gender.

Table 2: Pearson's r results on respondents marital status and health-seeking behaviour

\begin{tabular}{|l|l|l|l|l|l|l|}
\hline Variables & N & Df & R & Sig (2 tailed) & Alpha Level & Decision \\
\hline $\begin{array}{l}\text { Marital Status and } \\
\begin{array}{l}\text { Health-Seeking } \\
\text { Behaviour }\end{array}\end{array}$ & 1152 & 1150 & 0.098 & 0.001 & 0.05 & Rejected \\
\hline
\end{tabular}

$>0.05$ Alpha level of significant

Table 2 reveals the calculated $r$-value of 0.098 whose significant probability value ( $\mathrm{P}$ value) is 0.001 computed at alpha level of significance of 0.05 . Since the calculated p-value of 0.001 is less than 0.05 alpha level significance, therefore, the null hypothesis is rejected. The implication is that marital status of the respondents determines their health-seeking behaviour.

Table 3: Pearson's $r$ results on respondents religious affiliation and health -seeking behaviour

\begin{tabular}{|c|c|c|c|c|c|c|}
\hline & $\mathrm{N}$ & Df & $\mathrm{R}$ & Sig (2 tailed) & Alpha Level & Decision \\
\hline $\begin{array}{l}\text { Religious Affiliation } \\
\text { and } \\
\text { Health-Seeking } \\
\text { Behaviour }\end{array}$ & 1152 & 1150 & 0.149 & 0.000 & 0.05 & Rejected \\
\hline
\end{tabular}

$>0.05$ Alpha level of significant 
Table 3 shows 0.149 as the calcualted $r$-value with significant probability value ( $\mathrm{p}$-value) of o.ooo computed at alpha level of significance of 0.05 . Since the calculated p-value of 0.000 is less than 0.05 alpha level of significance, therefore, the null hypothesis is rejected. This means that religious affiliation difference determines the respodnents' healthseeking behaviour. This shows that religious belief of the individual dictates the health behaviour of the followers. Muslims and Christians differ in their beliefs as eating of certain food items is concerned.

\section{Regression}

Hypothesis 4: Gender, marital status and religious affiliation of the respondents would not have significant correlation on health-seeking behaviour of the people of Oyo State, Nigeria.

Table 4a: Result of regression analysis

\begin{tabular}{|l|l|l|l|l|l|l|}
\hline & Sum of Squares & Df & Mean Square & F & Sig & Decision \\
\hline $\begin{array}{l}\text { Regression } \\
\text { Residual }\end{array}$ & 21613.103 & 3 & 4543.736 & 30.598 & 0.000 & Rejected \\
\hline
\end{tabular}

Table 4b: Contribution of respondents gender, marital status and religious affiliation to their health-seeking behaviour

\begin{tabular}{|l|l|l|l|l|l|}
\hline & $\begin{array}{l}\text { Unstanderdized } \\
\text { Coefficients }\end{array}$ & $\begin{array}{l}\text { Unstanderdized } \\
\text { Coefficients }\end{array}$ & $\begin{array}{l}\text { Standerdized } \\
\text { Coefficients }\end{array}$ & & \\
\hline Model & $\mathrm{B}$ & Std. Error & Beta & $\mathrm{T}$ & Sig Decision \\
\hline Gender & 1.200 & .750 & .044 & 1.601 & .110 Not rejected \\
\hline Marital status & .814 & .468 & .050 & 1.741 & .002 Rejected \\
\hline Religion & -3.682 & .694 & .146 & 5.302 & .ooo Rejected \\
\hline
\end{tabular}

Table 4a shows that the calculated F-value is 30.598 with P-value of 0.000 computed at level of significance of 0.05 . Since the calculated P-value of 0.000 is less than 0.05 alpha level of significance, therefore, the null hypothesis is rejected. This, according to table $4 \mathrm{~b}$ implies that gender, marital status and religious affiliation significantly correlate the health-seeking behaviour of the people of Oyo State.The implication is that they contributed to the variance in their health-seeking behaviour. It was also revealed that gender $(t 1.601=.110)$ had no correlation with health-seeking behaviour of the people of Oyo State, as both male and female indulge in drinking, sedentary lifestyle, drug use and of course indiscriminate sexual behaviour. 
Table 4c: Result of model summary of regression analysis

\begin{tabular}{|l|l|l|l|l|}
\hline & $\mathrm{R}$ & R SQUARE & ADJUSTED R & STD ERROR OF THE ESTIMATE \\
\hline 1 & 0.367 & 0.158 & 0.153 & $12.18589 \mathrm{~s}$ \\
\hline
\end{tabular}

Table 4c Indicates that the independent variables ( gender, marital status and religious affiliation) contributed R2 $=0.158(15.8 \%)$ of the variance to health seeking behaviour of the people of Oyo State. It means that there are other factors such as ethnicity and sociocultural that health - seeking behaviour depends on because of the inability of gender, marital status and religious affiliation difference to make total contributions.

\section{Discussion of Findings}

This research work was designed to investigate the degree of correlation that exists among gender, marital status and religious affiliation on health-seeking behaviour of the people of Oyo State.

Considering the hypothsis 1 , the finding indicated that gender of the respondents had no significant correlation with health-seeking behaviour of the people of Oyo State. This signifies that the issue of male or female makes no difference in determining healthseeking behaivour of the people. Male and female need to maintain a healthy life no matter the condition. In corroborating this finding, Shehu et al. (2011) said that females are known to be physically inactive while males have a high physical activity related energy expenditure. Oboh, Ekpebu and Ode (2010) emphasized that males have the higher probability of accepting voluntary HIV counselling and testing services than their female counterparts because females are more vulnerable to HIV status.

The finding on hypothesis 2 revealed that marital status of the respondents had significant correlation with health seeking behaviour of the people of Oyo State. This implies that marital status is influential in determining the individual's health seeking behaviour. Harris and Thoresen (2005) supported this finding by claiming that maintenance of strong and healthy relationship through marriage has been linked to positive behaviour, increased longevity, fewer degenerative symptoms, better mental well-being and life satisfaction. Broadhead, Kapan and James (1983) claimed that risk factors for death and all causes of mortality are twice as high among the unmarried as the married. Shehu et al. (2011) noted that marriage relatives have positive effects especially on mental health.

The finding on hypothesis 3 stated that religious affiliation of the respondents significantly correlated with health seeking behaviour of the people of Oyo State. This means that the religious affiliation difference has positive or negative effects on healthseeking behaviour. This finding corroborates Ikulayo and Adekoya (2006), Afen and Taiwo (2007) and Abubakar (2011) who said that some religious groups view women 
participation in sports as anti religious because the sports wears that are smart looking could be offensive to some religious faith. Ekpu and Effiong (2010) submitted that nutrition taboos are inbuilt in different religions. For example, islamic religion prohibit eating of pork meat by Muslims, despite its nutritional value. Omary (2006) stressed that religious teaching is significantly influential to the acceptance of voluntary HIV counselling and testing because it is perceived as misleading to the society.

The finding on hypothesis four which combined the three variables, revealed that gender does not significantly correlate with the respodents health-seeking behaviour, marital status and religious affiliation significantly correlated with their health-seeking behaviour. It also shows that marital status and religious affiliation contributed $15.8 \%$ of the variance to their health-seeking behaviour. In corroborating this finding, Ekpu and Effiong (2010) submitted that nutritional taboos are inbuilt in different cultures and religion and that it is a known fact that food habits of people are guided by factors such as cultural beliefs, religion, customs, age, sex, health reasons and socio-economic considerations.

\section{Conclusion}

Religion and marital status of the respondents determine the health-seeking behaviour of the people, while gender does not significantly influence the health behaviour of the respondents. The study conclude that religious affiliation had significant correlation with health -seeking behaviour of the people. The implication is that different religion affiliations of Islam, Christianity and Traditional religions dictates the health behaviour of their followers.

There is the need for Educators and Religious Leaders to get actively involved in the campaign against unhealthy lifestyles of smoking,heavy alcohol consumption,sedentary lifestyle, indiscriminate sexual practices and abuse of drugs. This campaign would help to address religious taboos,beliefs and supersitions associated with nutrition and other health practices in the community.

It is recommended that, Health educators and religious leaders should jointly involve in the campaign against unhealthy lifestyles of smoking,heavy alcohol consumption,sedentary lifestyle,indiscriminate sexual practices and abuse of drugs. This campaign would help to address religious taboos, beliefs and supersitions associated with nutrition and other health practices in the community.

\section{References}

Abubakar, A. (2011). Socio-cultural factors and female participation in Sport in Colleges of Education in North Central Nigeria. Unpublished doctoral thesis. University of Ilorin, Ilorin, Nigeria. 
Adeniyi, T. and M. T. Ogunsola (2009). Nature and nurture as determinants of health status among secondary school students in Atiba local government, Oyo State. COEASU book of Readings: A Multidisciplinary studies. A publication of Federal College of Education Abeokuta, Nigeria. (2), pp.56-63.

Afen, O. P. and M. T. Taiwo (2007). Influence of gender and parental approval on sports socialization of the citizenry.In N. I. Nzoem, S. Arogbonlo \& K. O. Omolawon (Ed.) Journal of sports management and educational research 1 (3), pp.18-22

Agbeko, W. W. (2010). Predictors of socio-cultural health related risky - behaviours among in-school adolescent in Nigeria and Ghana. Unpublished doctoral field proposal. University of Ibadan, Ibadan, Nigeria.

Broadhead, W. E., B. H. Kapan and S. James (1983). The Epidemologic Evidence for a Relationship between social support and Health. American Journal of Epidemiology.117(5):521-537.

Ekpu F. S and E. A. Effiong (2010). Socio-cultural determinants of the nutritional status of pregnant women attending St. Lukes Hospital, Anua, Uyo, Akwa Ibom State. Nigerian Journal of Health Education. 14 (1), pp.62-66.

Emiola, M. L. (2007). Tips on how to maintain a fit and healthy body. Journal of Nigerian Association of Sport Science and Medicine.(6)15-16.

Fawole, I., F. O. Egbekhare, A. O. Itiola, A. I. Odejide and A. I. Olayinka (2006). Definition,Spectrum and Type of Research. In V.O.Taiwo, A. Raji-Oyelade and I.P. Farai (Eds.) Publication of the Postgraduate School,University of Ibadan, Nigeria.

Fisher, A. A., Laing, J. E. Stoeckel, J.E. and Townsend, J. W. (1998). Handbook for Family Planning Operations Research $\left(2^{\text {nd }}\right.$ ed.). New York. Population Council Publication, 40-44.

Harris, AHS., and C. E. Thoresen (2005). Volunteering is associated with delayed mortality in older people. Analysis of the longitudinal study of aging. Journal of Health Psychology. (6):739-752.

Ikulayo, P. B. and A. F. Adekoya (2006). Role of women in sport delivery system in achieving the millennium development goals. A. Onifade (Ed.) Proceeding of the $37^{\text {th }}$ Conference of Nigerian Association of Physical, Health Education, Recreation-Sports and Dance, Mosogar: Yomleks Press Ltd.

Kay, T. (2006). Daughter of Islam. Family influence on Muslim young women's participation in sports. Loughborough University. U.K. (Online chew loaded). http://irs.sagepub. com/egicontentabstract/41/3-4/357. Retrieved on 8/04/2008. 
National Population Commission (2006). Population statistics,map and location:Oyo State of Nigeria.National Population Census. http:www.citypopulation.de/php/ nigeria-admin.php?admıid=NGAo31

Oboh, V. U., I. D. Ekpebu and A. V. Odeh (2010). Knowledge and acceptability of voluntary counselling and test (VCT) for HIV/AIDs by rural farmers in Benue State, Nigeria. Nigerian Journal of Health Education. (1), pp. 81-86.

Omary, s. (2006). Barriers and attitudes towards HIV voluntary couselling and testing (VCT) among secondary school pupils of Sengerema in Mwanza, Tanzania.Tanzania Medical Journal. Official Publication of the Tanzania Medical Students' Association (1), pp. 12-16.

Shehu, R. A. (2005). Relationship between demographic factors and lifestyle of the people of Kaduna State, Nigeria. Unpublished doctoral dissertation. Ahmadu Bello University, Zaria, Nigeria.

Shehu, R. A., L. A. Yahaya, S. A. Onasanya, E. A. Ogunsakin and S. O. Oniyangi (2011). Influence of Demographic Factors on the lifestyles of students of Tertiary Institution in Kwara State, Nigeria. Journal of Research in Education An official Journal of the collaboration of Education Faculties in West Africa Journal. (1), pp. 89-96. 